\title{
Mitral valve replacement by a Gore-Tex reinforced pulmonary autograft in a child
}

\author{
Masaaki Yamagishi, MD, Keisuke Shuntoh, MD, Tsutomu Matsushita, MD, \\ Katsuji Fujiwara, MD, Takeshi Shinkawa, MD, Takako Miyazaki, MD, and \\ Nobuo Kitamura, MD, Kyoto, Japan
}

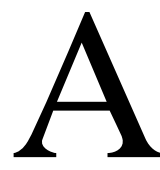

lthough some positive results have been reported ${ }^{1,2}$ for the Ross II operation, which entails mitral valve replacement using a pulmonary autograft, ${ }^{3,4}$ this procedure has not become common because it involves difficult maneuvers. However, this procedure is suitable for children with irreparable mitral valve disease. In this report, we described a unique method of preparing the pulmonary autograft and performing the Ross II operation on a child with intractable mitral valve regurgitation.

\section{Clinical Summary}

A girl with partial atrioventricular septal defect, dysplastic mitral valve, and severe mitral valve regurgitation underwent mitral valvuloannuloplasty and closure of an atrial septal defect at 2 months of age. Because of severe residual mitral regurgitation and congestive heart failure, the mitral valve was replaced by a $16-\mathrm{mm}$ ATS valve (ATS Medical, Inc, Minneapolis, Minn) at 3 months of age. One year later, the prosthetic valve malfunctioned due to pannus formation. Cardiac catheterization demonstrated that 1 disk of the valve was stuck, resulting in a systolic pulmonary arterial pressure of $60 \mathrm{~mm} \mathrm{Hg}$. Angiography revealed that the pulmonary annular diameter was $16 \mathrm{~mm}$, which is $106 \%$ of the normal mitral annular value.

A third operation was performed at 11 months of age. Before the operation, the external cylinder of the pulmonary autograft was prepared. According to the diameter of the pulmonary artery, a 16-mm polytetrafluoroethylene (PTFE) graft (Gore-Tex; W. L. Gore \& Associates, Inc, Flagstaff, Ariz) was chosen as the external cylinder. As a sewing cuff, a PTFE felt strip $1 \mathrm{~mm}$ in thickness and $5 \mathrm{~mm}$ in width was looped around and sewn firmly onto the outer surface of the Gore-Tex graft using a Gore-Tex running suture (Figure 1). After establishing a hypothermic cardiopulmonary bypass and crossclamping the aorta, the right-sided left atrium was incised longitudinally. The ATS valve together with its sewing cuff was completely resected. After the pannus tissue was resected as much as possible, a 16-mm sizer was passed, with difficulty,

From the Department of Pediatric Cardiovascular Surgery, Children's Research Hospital, Kyoto Prefectural University of Medicine, Kyoto, Japan.

Received for publication Jan 15, 2003; accepted for publication March 24, 2003.

Address for reprints: Masaaki Yamagishi, MD, Department of Pediatric Cardiovascular Surgery, Children's Research Hospital, Kyoto Prefectural University of Medicine, Kawaramachi, Hirokoji, Kamikyo-ku, Kyoto, 6028566 Japan (E-mail: myama@koto.kpu-m.ac.jp).

J Thorac Cardiovasc Surg 2003;126:1218-9

Copyright $(2003$ by The American Association for Thoracic Surgery $0022-5223 / 2003 \$ 30.00+0$

doi:10.1016/S0022-5223(03)00785-2 through the annulus. Because the subannular ventricular space was still very narrow, we decided not to reimplant the

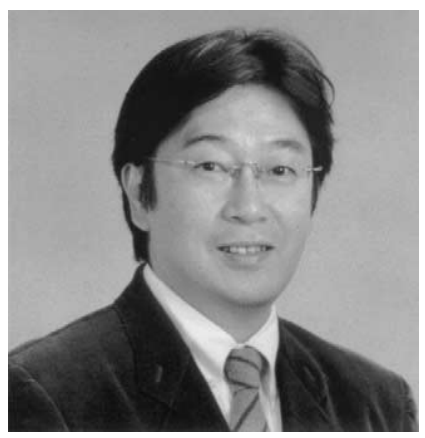

Dr Yamagishi prosthetic valve and instead performed a Ross II operation.

For the Ross II operation, a pulmonary autograft was harvested in the usual manner. The subvalvular muscular tissue of the pulmonary autograft was trimmed to a width of $3 \mathrm{~mm}$ and the Gore-Tex graft was cut with the PTFE band positioned in its center. The length of the graft was matched to the height of the commissure. The pulmonary autograft was put into the Gore-Tex graft and the muscular layer was anastomosed to the end of the Gore-Tex graft using a 5-0 polypropylene running suture (Figure 2, A). The other end of the Gore-Tex graft was scooped out to fit the sinus Valsalva and the distal end of the autograft was anastomosed to the Gore-Tex graft using a 5-0 polypropylene running suture (Figure 2, B). The height of the left ventricular part of the Gore-Tex external cylinder was low. The pulmonary autograft bearing the Gore-Tex external cylinder was inserted into the mitral annulus, and the PTFE felt band around the Gore-Tex external cylinder was anastomosed to the annulus using interrupted mattress sutures. The implanted graft did not protrude into the left atrium (Figure 3).

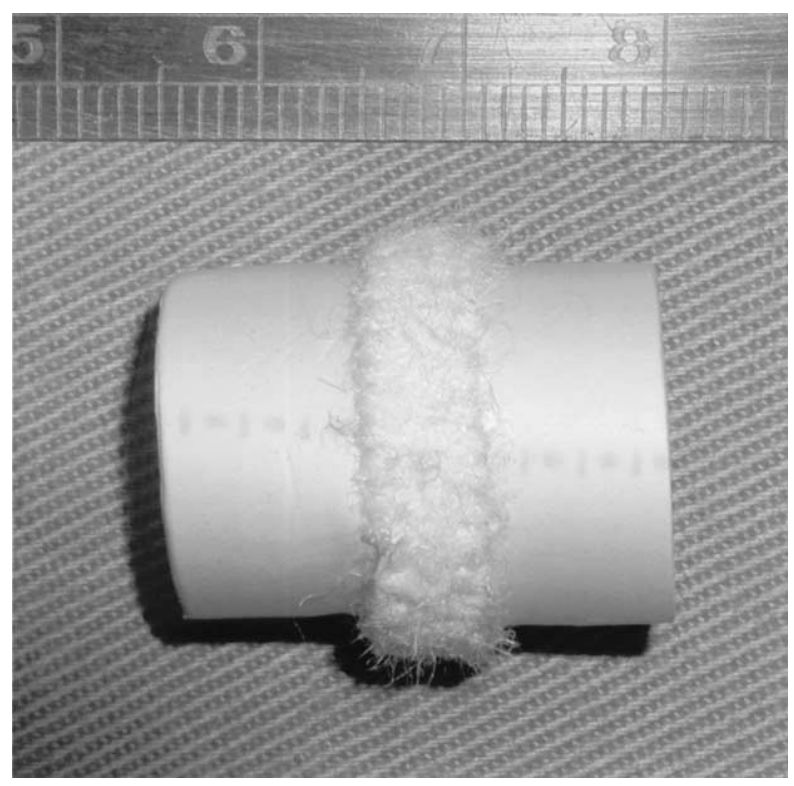

Figure 1. The Gore-Tex external cylinder (before final trimming). A 5-mm wide PTFE felt strip, which was used as a sewing cuff, was looped around the Gore-Tex graft and sewn onto its outer surface using a Gore-Tex running suture. 

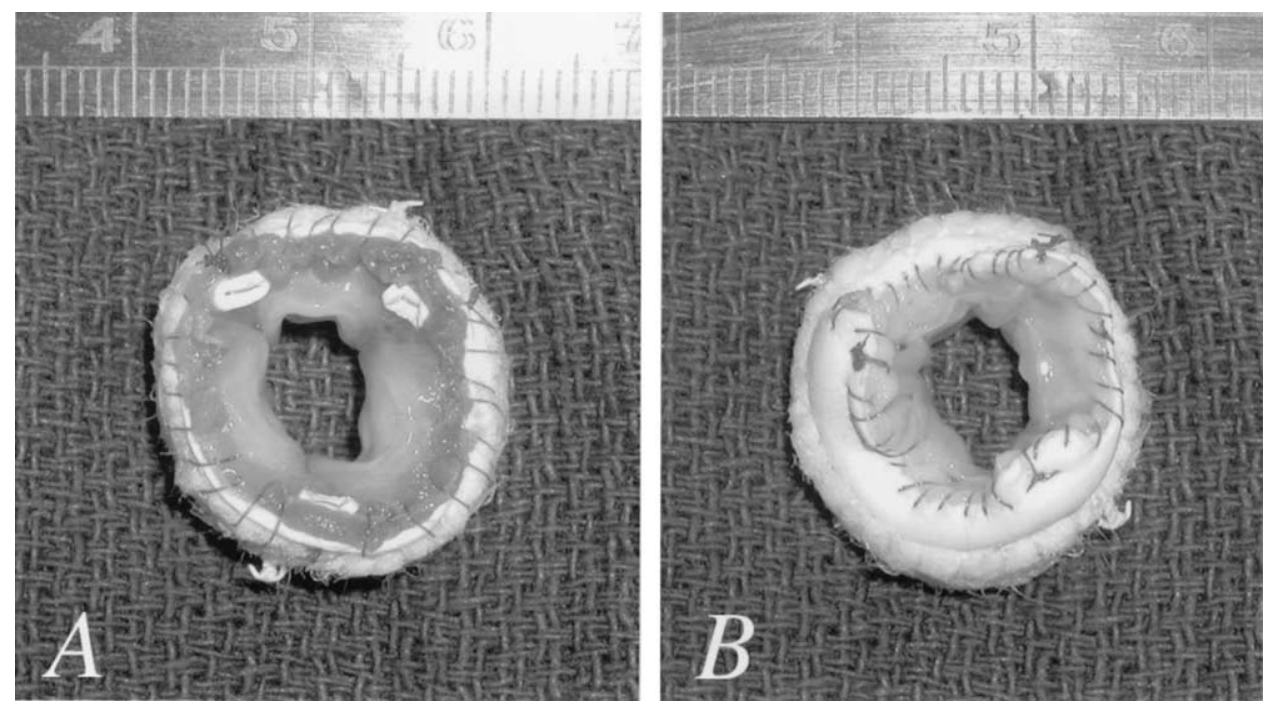

Figure 2. A, Left atrial aspect of the pulmonary autograft bearing the Gore-Tex external cylinder. The muscular layer of the autograft was anastomosed to the Gore-Tex graft using a 5-0 polypropylene running suture. B, Left ventricular aspect of the pulmonary autograft. The end of the Gore-Tex graft was scooped out to fit the sinus Valsalva.

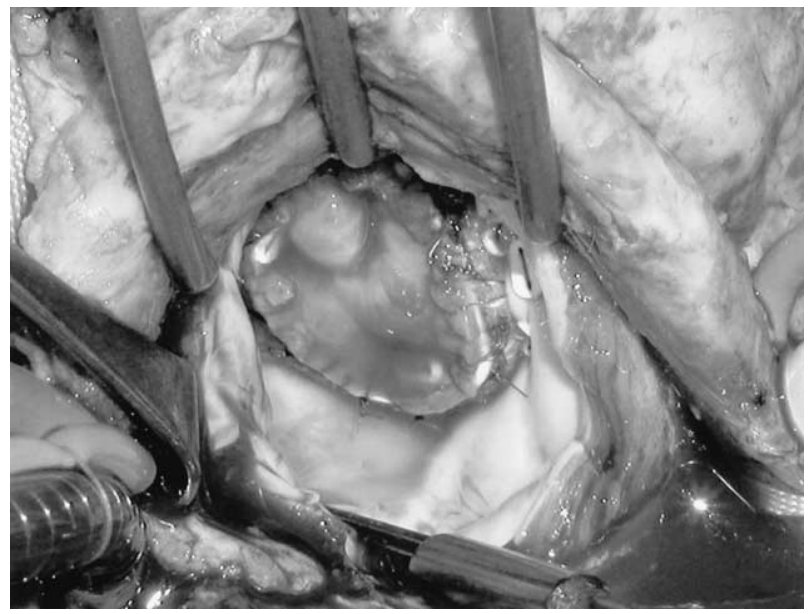

Figure 3. The PTFE felt band around the Gore-Tex external cylinder was anastomosed to the mitral annulus using interrupted mattress sutures. The implanted graft did not protrude into the left atrium.

Doppler echocardiography 5 months after the operation demonstrated that neither significant mitral regurgitation nor left ventricular outflow obstruction were detected.

\section{Discussion}

There are many morphologic restrictions in repairing the mitral valve in children. Replacement of the affected mitral valve is often necessary when there is a major disorder of the subvalvular apparatus or when there is severe leaflet degeneration. For replacement of the mitral valve in children, pulmonary autograft is preferred over commercially available prosthetic valves or mitral homograft.
The external wall of the pulmonary autograft ${ }^{1-5}$ is usually reinforced by a Dacron graft to avoid longitudinal deformation. In addition to lengthwise reinforcement, stronger crosswise reinforcement is recommended to avoid constriction of the autograft because the pulmonary autograft is vulnerable and the mitral annulus is narrow in children. For this reason, the Gore-Tex graft as an external cylinder is recommended. Although the top hat method ${ }^{5}$ helps to prevent obstruction of the left ventricular outflow, in children the left atrium is too small for the original top hat method. Therefore, the sidewall of the Gore-Tex external cylinder was fitted to the mitral annulus, such that neither end of the graft protruded into the left atrium or the left ventricle. To create a margin for suturing, a preanastomosed PTFE felt around the Gore-Tex graft was used.

The drawback of this technique is that the autograft enclosed within the Gore-Tex graft is unviable. However, the Ross II operation compensates adequately in children with an irreparable mitral valve. The next generation of outer shell, which offers growth potential, is awaited.

\section{References}

1. Kabbani SS, Jamil H, Hammoud A, Nabhani F, Hariri R, Sabbagh N, Ross DN. Use of the pulmonary autograft for mitral replacement: short- and medium-term experience. Eur J Cardiothorac Surg. 2001;20:257-61.

2. Al Halees Z, Awad MM, Pieters F, Shahid MS, Al Amri MA. Six-year follow-up of a pulmonary autograft in the mitral position: the Ross II procedure. J Thorac Cardiovasc Surg. 1999;117:614-6.

3. Kabbani SS, Ross DN, Jamil H, Hammoud A, Nabhani F, Hariri R, Kabbani LS. Mitral valve replacement with a pulmonary autograft: initial experience. J Heart Valve Dis. 1999;8:359-67.

4. Kumar AS, Aggarwal S, Choudhary SK. Mitral valve replacement with the pulmonary autograft: the Ross II procedure. J Thorac Cardiovasc Surg. 2001;122:378-9.

5. Ross DN, Kabbani S. Mitral valve replacement with a pulmonary autograft: the mitral top hat. J Heart Valve Dis. 1997;6:542-5. 